The Efficacy of Low Vision Devices for Students in Specialized Schools for Students who are Blind in Kathmandu Valley, Nepal

Joshi, Mahesh Raj

http://hdl.handle.net/10026.1/16300

10.1177/0145482x0810200706

Journal of Visual Impairment \&amp; Blindness

SAGE Publications

All content in PEARL is protected by copyright law. Author manuscripts are made available in accordance with publisher policies. Please cite only the published version using the details provided on the item record or document. In the absence of an open licence (e.g. Creative Commons), permissions for further reuse of content should be sought from the publisher or author. 


\section{The Efficacy of Low Vision Devices for Students in Specialized Schools for Students Who Are Blind in Kathmandu Valley, Nepal}

Article in Journal of visual impairment \& blindness · July 2008

CITATIONS

2

4 authors, including:

\section{Mahesh Raj Joshi}

Glasgow Caledonian University

13 PUBLICATIONS 38 CITATIONS

SEE PROFILE
Suraj Shakya-Vaidya

University of St Andrews

31 PUBLICATIONS 182 CITATIONS

SEE PROFILE 


\section{The efficacy of low vision devices for students specialized schools for students who are blind in Kathmandu Valley, Nepal. \\ Print}

Author:
Joshi, Mahesh R.; Yamagata, Yoshitaka; Akura, Junsuke; Shakya, Suraj

Geographic Code: 9NEPA

Date:

Jul 1, 2008

Words: 2868

Publication: ISSN:

\section{Journal of Visual Impairment \& Blindness}

0145-482X

Abstract: In Nepal, children with low vision attend specialized schools for students who are totally blind and are treated as if they were totally blind. This study identified children with low vision and provided low vision devices to them. Of the $22 \%$ of the students in the school who had low vision, $78.5 \%$ benefited from the devices. Proper devices and counseling improved the quality of life of a significant number of these students.

Ninety percent of people who are blind are in developing countries. Because of the lack of proper eye care facilities, their number is increasing at an alarming rate because people in developing countries are 10 times more likely to go blind than are those who live in industrialized countries (Holden, 2000).

In Nepal, most causes of childhood blindness are preventable, although a large populationbased survey has not been conducted in the past 27 years. The 1981 Nepal Blindness Survey reported that infectious diseases $(21.3 \%)$ and nutritional diseases $(17.9 \%)$ are the major causes of childhood blindness, followed by cataract (16.3\%) and trauma (9\%) (Brilliant, Pokhrel, Grasset, \& Brilliant, 1988). Furthermore, no study has reported the number of children with low vision, but the number of those with low vision could be significant, since a more-recent study in Nepal showed that about $15 \%$ of the children at a specialized school for students who are blind (hereafter, specialized school) had low vision (Khanal, 2001).

Since the concept of low vision has recently been introduced in Nepal, few individuals with low vision have benefited from rehabilitation services. The first National Workshop on Low Vision in Nepal was held on November 2004 after the World Health Organization endorsed the definition of low vision and provided guidelines for the development of National Low vision Policy. Historically, individuals with low vision in Nepal have been forced to live like those who are totally blind because of the lack of proper devices and trained personnel to serve this population. In Nepal, there are a few specialized schools for students who are visually impaired or for those who are blind and have other disabilities, either in the capital, Kathmandu, or in other parts of the country, that provide students with basic education and other vocational training. Children who are visually impaired are also sent to the Nepal Association of the Blind for orientation and mobility training, if necessary. 
All students who are visually impaired are first examined at various eye hospitals and centers throughout the country, after which they are referred to specialized schools or schools where children with special needs are served. Because of the lack of separate schools for children with low vision, all students who are visually impaired are sent to the specialized schools. Since there have been no initiatives to separate those with low vision from those who are totally blind, children with low vision have been forced to learn and work as if they are blind. If children with low vision could be identified and provided with proper low vision devices, they could live more comfortably. Thus, our study was designed to identify students with low vision and to provide them with proper optical and nonoptical devices.

\section{Materials and methods}

Two specialized schools for students who are blind and one school serving students with special needs in Kathmandu Valley were included in the study. Optometrists and ophthalmologists visited the schools to screen all the students. Detailed ocular examinations were conducted. First, an examination form was used to gather information on a student's ocular and systemic history and to enter the findings of the ocular examination, the causes of visual impairment, and the trial with the low vision devices. Each student received a visual acuity evaluation (the Bailey-Lovie chart), an anterior and posterior segment examination, and an evaluation for refractive errors. Students whose vision could be improved were transported to the base hospital for a further low vision evaluation. After the complete evaluation was finished and the necessary low vision devices were provided, the students were referred to the Nepal Association of the Blind for mobility and other vocational training.

\section{FOLLOW-UP AND SATISFACTION SURVEY}

We went back to these schools to evaluate any changes in the daily lives of the students who had received the low vision assessment and devices after time periods of one month and six months following the initial intervention. The students' responses regarding the implications of the low vision devices for the quality of their lives were recorded on the form with a special questionnaire. The teachers were interviewed about the changes in the students' lifestyles with the use of the devices or, if use of the devices was discontinued, the reasons why the devices were discontinued.

\section{Results}

A total of 62 students, 41 boys and 21 girls, were screened. Of that number, 48 (33 boys and 15 girls) were blind; 32 had visual acuities of 20/1200 to light perception; and 16 were completely blind with no light perception. The remaining 14 students had low vision, accounting for $22.6 \%$ of the total number. Of these 14 students, 8 had mild visual impairments (acuities of 20/60 to 20/200) and 6 had severe visual impairments (20/200 to 20/400) (see Table 1). Among the 14 students with low vision, 8 (57\%) were boys and 6 (43\%) were girls; they ranged in age from 9 to 17 years (see Table 2).

With regard to the causes of blindness, traumatic and infectious corneal diseases leading to eventual staphyloma and phthisis bulbi were the major causes (47.9\%), followed by optic atrophy and congenital glaucoma (see Table 3). Among the various causes of low vision, optic atrophy accounted for the majority of the cases: 6 (43\%) of the 14 students. Among the students with optic atrophy, 2 had associated strabismus. Congenital nystagmus and colobomas accounted for 3 cases each. One student each was found to have corneal opacity 
(with a rejected graft) and oculocutaneous albinism (see Table 4).

\section{LOW VISION EVALUATION}

Eleven of the 14 students (78.5\%) benefited from low vision devices. The 3 students whose vision did not improve with the devices had severe visual impairments (acuities of 20/20020/400). Among the 62 students who were presumed to be blind, the conditions of $17.7 \%$ changed to low vision with the use of low vision devices. Of the 11 students who benefited from the low vision devices, 4 had used low vision devices in the past but had discontinued using them, 1 had lost the device and could not replace it, 2 had used spectacle microscopes, and 1 had use a handheld magnifier. Of the 2 who had used spectacle microscopes, poor illumination was a problem for 1 , while insufficient near vision with the present spectacles was a problem for the other. For the 1 who had used a handheld magnifier, difficulty writing with it was the problem.

The evaluation of the students with low vision revealed that of the 11 students with low vision, 10 had some form of refractive error, the correction of which led to at least a one-line improvement in acuity on the Snellen chart. After the full refractive correction, the students were given a low vision evaluation with various low vision devices. Refractive eyeglasses were provided to the 10 students, all of whom benefited from them. In addition to the eyeglasses, 3 students received telescopes for distance vision. Photochromatic lenses were provided to 3 students, and a student with oculocutaneous albinism received sun lenses with a tint and ultraviolet protection.

Most of the students were keen on improving their near acuity to help them with their learning activities. After the evaluation with near vision devices, 2 students did not want to use these devices because their near vision with distance correction in good illumination was sufficient for their near tasks. Among 9 other students, 6 were given spectacle microscopes only, 2 were given internally illuminated magnifiers, and 1 was given both a spectacle microscope and a handheld magnifier. All the students had near acuities of $1.25 \mathrm{M}$ or better with their respective devices.

\section{ONE-MONTH AND SIX-MONTH FOLLOW-UPS}

At the time of the one-month follow-up, all the students said that the low vision devices they had received were very useful, especially for reading and writing. One was using the device for reading for a long period of time and complained of eyestrain, so he was advised to rest between the surveys. Among the students who were using low vision devices, $72.7 \%$ said that they had better mobility, and $45.4 \%$ said they had better visualization and could recognize people.

The teachers who were interviewed said that all the children who were provided with low vision devices were using them regularly and that all these students were reading print and writing print instead of using braille. The teachers could see the changes in their lifestyles pertaining to improved mobility and the better performance of day-to-day tasks. In addition, they noticed the students' significantly elevated confidence in their academic performance compared to before the devices were prescribed.

At the time of the six-month follow-up, 1 of the 11 students was not present. The remaining 10 students were satisfied with the devices they were using and wanted to continue to use them. 


\section{Discussion}

In our study, $22.6 \%$ of the 62 students who were screened at the specialized schools were found to have low vision rather than being totally blind. A study conducted in specialized schools in Andhra Pradesh, India, reported functional low vision in 39.2\% of the students (Hornby et al., 2000). In a study of 26 students, $46 \%$ were found to have low vision, and $53.8 \%$ were found to be totally blind (Montilha, Temporini, Nobre, Gasparetto, \& Kara-Jose, 2006). There seems to be greater difference in the number of children with low vision in our study than in the other studies, but this difference could be due partly to the different methods of screening that were used to detect low vision in these studies. The other reason could be that this study was conducted in just the capital city of Nepal, which probably has a better referral system than do the peripheral parts of the country. A study with a larger sample incorporating specialized schools in other areas of Nepal could provide substantial information regarding the prevalence of low vision in the schools for students who are blind.

In our study, the students ranged in age from 9 to 17 years. A study done in the Czech Republic also reported that children in specialized schools ranged in age from 6 to 15 years (Kocur, Kuchynka, Rodny, Barakova, \& Schwartz 2001). Among the 48 children who were blind in our study, $47.9 \%$ were blind because of traumatic and infectious corneal diseases, followed by optic atrophy and congenital glaucoma. Optic atrophy was the leading cause of visual impairment, accounting for $43 \%$, followed by congenital nystagmus $(21.5 \%)$ and chorioretinal colobomas (21.5\%). Similar causes of blindness were reported in the 1981 Nepal Blindness Survey (Brilliant et al., 1988), the leading causes being infectious and nutritional diseases. Yorston (1999) also found that corneal disorder was the leading cause of blindness in children in low-income countries, followed by cataract and glaucoma. A study of specialized schools in India reported that corneal staphyloma, scars, and phthisis bulbi were the major causes of blindness and low vision (26.4\%), followed by microphthalmos, anophthalmos, and colobomas (Rahi, Sripathi, Gilbert, \& Foster, 1995). In contrast, a study at the Royal Blind School in Edinburgh reported that perinatal-related blindness was a major cause $(40 \%)$, followed by hereditary diseases (26\%) and developmental factors (26\%) (Alagaratnam, Sharma, Lim, \& Fleck, 2002). This discrepancy in the major causes of blindness and low vision in developing and developed countries could be due to differences in socioeconomic status.

Our study found that both the near and distance vision of 11 of the 14 children with low vision improved with the low vision evaluation and provision of low vision devices. Similarly, studies in South America (Ager, 1994) and West Africa (Ager, 1996) found that the distance or near visual acuity or both of approximately half the children with low vision at schools for students who are blind improved if the children were carefully refracted and supplied with appropriate spectacles and magnifiers. A study of specialized schools in East African countries also reported that the vision of $79 \%$ of the students improved either with eyeglasses or low vision devices (Silver, Gilbert, Spoerer, \& Foster, 1995). And a study in Madurai, India, showed the beneficial effects of low vision devices (Vijaylakshmi, 1998).

Most of the low vision devices provided to the students in our study were locally manufactured, including all the refractive eyeglasses, spectacle magnifiers, and handheld magnifiers. Similarly, a study conducted in specialized schools of East Africa reported that the locally manufactured devices could meet two-thirds of the need for low vision devices (Silver et al., 1995). In conclusion, the use of low vision devices can increase students' options for accessing regular print if they are prescribed appropriate low vision devices and taught to use them. 


\section{References}

Ager, L. R. (1994). Identifying children with low vision who benefit from magnifiers: A visual assessment of children at schools for the blind in Colombia and Ecuador. Unpublished M.Sc. thesis, International Centre for Eye Health, London.

Ager, L. R. (1996). Annual report of low vision services: Ghana National Eye Care program. London: International Centre for Eye Health.

Alagaratnam, J., Sharma, T. K., Lim, C. S., \& Fleck, B. W. (2002). A survey of visual impairment in children attending the Royal Blind School, Edinburgh, using the WHO childhood visual impairment database. Eye, 16, 557-561.

Brilliant, G. E., Pokhrel, R. P., Grasset, N. C., \& Brilliant, L. B. (1988). The epidemiology of blindness in Nepal: Report of the 1981 Nepal Blindness Survey. Chelsea, Ml: Seva Foundation.

Holden, B. (2000). Guest editorial: The right to sight. Clinical and Experimental Optometry, 83, 113-115.

Hornby, S. J., Adolph, S., Gothwal, V. K., Gilbert, C. E., Dandona, L., \& Foster, A. (2000). Evaluation of children in six blind schools of Andhra Pradesh. Indian Journal of Ophthalmology, 48, 195-200.

Khanal, S. (2001). Evaluation of causes of visual impairment in students of blind schools in Kathmandu Valley. Unpublished master's thesis, Tribhuvan University, Kathmandu, Nepal.

Kocur, I., Kuchynka, P., Rodny, S., Barakova, D., \& Schwartz, E. C. (2001). Causes of severe visual impairment and blindness in children attending schools for the visually handicapped in the Czech Republic. British Journal of Ophthalmology, 85, 1149-1152.

Montilha R. C., Temporini, E. R., Nobre, M. I., Gasparetto, M. E., \& Kara-Jose, N. (2006). Utilization of optical devices and equipment by students with visual impairment. Arquivos Brasileiros de Oftalmologia, 69, 207-211.

Rahi, J. S., Sripathi, S., Gilbert, C. E., \& Foster, A. (1995). Childhood blindness in India: Causes in 1,318 blind school students in nine states. Eye, 9, 545-550.

Silver, J., Gilbert, C. E., Spoerer, P., \& Foster, A. (1995). Low vision in East African blind school students: Need for optical low vision services. British Journal of Ophthalmology, 79, 814-820.

Vijaylakshmi, P. (1998). Children in blind schools: What condition should be treated? Community Eye Health, 11, 35-36. Yorston, D. (1999). The Global Initiative; Vision 2020, Childhood Blindness. Community Eye Health, 12, 44-45.

We are highly obliged to the Association for Ophthalmic Cooperation to Asia for providing a low vision trial set for this study. Our sincere thanks go to Rajesh K. Sharestha, M.D.; Rabindra Ghising, B.Optom.; and Pooja Pradhan, B.Optom. for their immense contributions to the data collection and analysis. We are also thankful to Om Hospital and Research Centre 
for providing logistical support during this work.

Mahesh R. Joshi, B. Optom., Om Hospital and Research Center, P. O Box 13494, Chabahil, Kathmandu, Nepal; e-mail: <mahesh_raj@ hotmail.com>. Yoshitaka Yamagata, M.D., Hyogo College of Medicine, 1-1 Mukogawa-cho, Nishinomiya, Huogo, 663-8501, Japan; Junsuke Akura, M.D., Ph.D., Kusumoto Rehabilitation Centre, Wakayama, Osaka, Japan; e-mail: <info@aoca.jp>. Suraj Shakya, M.S., Om Hospital and Research Center, P. O Box 13494, Chabahil, Kathmandu, Nepal; e-mail: <suraj_bpkeye@hotmail.com>.

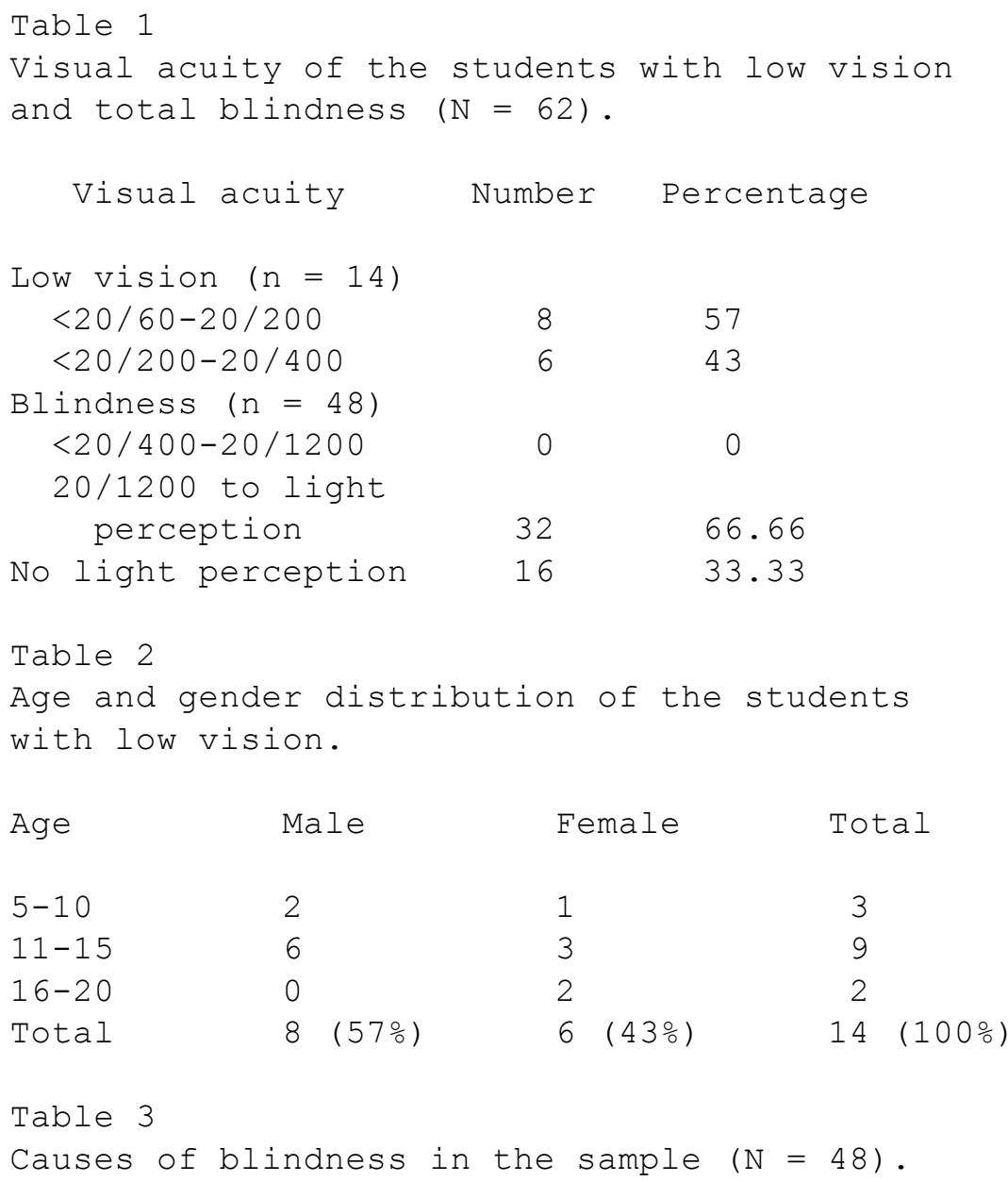


Causes Number Percentage

Optic atrophy (with

strabismus-2) 643.0

Congenital nystagmus $\quad 3 \quad 21.5$

Coloboma (chorioretinal) $\quad 3 \quad 21.5$

Albinism $\quad 1 \quad 7.0$

Corneal opacity $\quad 1 \quad 7.0$

COPYRIGHT 2008 American Foundation for the Blind

Copyright 2008 Gale, Cengage Learning. All rights reserved. 